\title{
Timeline Approach for the Treatment of COVID-19 - An Overview
}

\author{
Pavani Polipilli ${ }^{1}$, Vishnu Vamsi Nannur ${ }^{2}$, Bharathi Vudi ${ }^{3}$, \\ Sai Durga Yakkaladevara ${ }^{4}$, Yasa Sree Reemali ${ }^{5}$, J John Kirubakaran ${ }^{6}$ \\ ${ }^{1-6}$ Vikas Institute of Pharmaceutical Sciences, Nidigatla village, Korukonda Mandal, Rajahmundry, \\ Andhra Pradesh, 533103, India.
}

Corresponding Author: Sai Pavani Polipilli

DOI: https://doi.org/10.52403/ijrr.20220221

\section{ABSTRACT}

The outbreak of novel CORONA virus has taken many lives since the onset of the pandemic. On December 31, 2019, the World Health Organization received reports of pneumonia with an unknown aetiology in the Chinese city of Wuhan. Chinese officials discovered a new coronavirus as the source of the outbreak on 7 January 2020, provisionally named "2019-nCoV." The World Health Organisation has recorded 4,215,966 confirmed cases and 79,758 fatalities by the end of December 2020, both of which have been raised quickly. The main symptoms of this disease that were recorded so far include fever in $85 \%$ of patients, dyspnoea in $70-80 \%$, cough in 40 $80 \%$, smell and taste dysfunction in $50 \%$, myalgia in $30 \%$, and gastrointestinal problems in $10-30 \%$. To reduce the count of patients entering into severity phase many diagnostic criteria were employed that includes Reverse Transcriptase Polymerase Chain Reaction test, High Resolution Computed Tomography scan, measuring the levels of Creatinine Reactive Protein, Domain Dimer, Serum Ferritin to assess the level of inflammation. Nevertheless, of all the treatment strategies employed by various researchers, doctors, scientists, and vast number of organizations and institutions, this review article provides the treatment strategies to treat Covid-19 according to the timeline progression of the disease, gleaning the information from various sources. The treatment protocol includes the right time diagnosis and starting the treatment with remdesivir, corticosteroids, antiplatelet agents and Interleukin-6 inhibitors, Janus Kinase inhibitors basing on the severity of
\end{abstract}

the disease. But the crucial part to treat Covid19 lies in establishing the right therapy at the right time.

Keywords: Remdesivir; Corticosteroids; Antiplatelet agents; Cytokine storm; C-reactive protein; D-Dimer; Serum ferritin; RT-PCR, Janus kinase inhibitors.

\section{INTRODUCTION}

On December 31, 2019, the World Health Organization (WHO) received reports of pneumonia with an unknown aetiology in the Chinese city of Wuhan. Chinese officials discovered a new coronavirus as the source of the outbreak on 7 January 2020, provisionally named "2019nCoV. In light of Covid-19 pandemic, this article provides you with a timeline strategies in order to treat covid-19 disease.

Infectious disorders caused by Coronaviruses (CoV) range from the common cold to more severe diseases. A new coronavirus $(\mathrm{nCoV})$ is a strain of coronavirus that has never been learned previously in humans and is thus considered novel. The COVID-19 virus was the name given to the novel virus when it was discovered[1]. Symptoms range from moderate to severe, and severe pneumonia is a possibility. The case fatality rate is 2.3 percent, and the criticality rate is 49.5 percent, according to the Centres for Disease Control and Prevention[2]. The most frequently encountered clinical 
characteristics in early clinical cases from Wuhan, China, were fever (98.6 percent), fatigue (69.6 percent), and a dry cough (69.6 percent) (59.4 percent)[3]. Despite China's rapid response and stringent disease containment measures[4]. COVID-19 has rapidly vast number of countries within a short span of time and has developed into a pandemic $[5,6]$.

Dr. Tedros Adhanom Ghebreyesus who is the Director-General of the World Health Organization (WHO), declared the novel coronavirus outbreak a public health emergency of international concern (PHEIC) on 30 January 2020, the highest level of alarm set by the WHO[7]. At the time, there were 98 instances reported in 18 countries other than China, with no fatalities[1].

The WHO has recorded 4,215,966 confirmed cases and 79,758 fatalities by the end of December 2020, both of which have been raised quickly. Covid-19 has been linked to $187,519,798$ confirmed cases and $4,049,372$ fatalities as of July 14, 2021[8].

\section{Aetiology of SARS-CoV-2:}

Severe acute SARS-CoV-2 is a new $\beta$ coronavirus identified in bronchoalveolar lavage samples from patients with pneumonia of unclear origin in Wuhan City, Hubei Province, China, in December 2019[9].

Coronaviruses are named for the crown-like spikes on their surface[10]. SARS-CoV-2 is the seventh coronavirus to infect people and is classified as a Sarbecovirus. Similar to SARS-like coronaviruses identified in bats, but different from SARS-CoV and MERSCoV[11]. The full genome has been determined and published in GenBank.

In 1960, Human coronaviruses were first identified. Seven corona viruses that can infect people were identified and named them as:

229E (alpha coronavirus)

NL63 (alpha coronavirus)

OC43 (beta coronavirus)

HKU1 (beta coronavirus)

\section{MATERIALS AND METHODS}

This study was made by searching the literature in databases such as PubMed, science Direct, The Lancet, Google scholar, Web of science, ERIC and references to identify articles were made using search terms such as timeline to treat Covid-19, timeline progression of Covid-19 disease, cytokine storm, Coagulopathy, D-Dimer, Serum Ferritin, C-Reactive Protein, Remdesivir, Monoclonal antibodies, Dexamethasone, Corticosteroids, Antivirals, Anti platelets. This review includes the articles which manifests the treatment strategies for Covid-19.

\section{Pathophysiology Of SARS-COV-2:}

The virus is transmitted from person to person via the exchange of respiratory droplets and aerosolized particles and it enters the body by attaching itself to host receptors and then entering host cells via endocytosis or membrane fusion, depending on the kind of virus[12]. The SARS-CoV receptor ACE-2 has been identified as a functional receptor on pulmonary epithelial cells, and it is found in high levels on these cells[13]. Following membrane fusion, the virus penetrates the alveolar epithelial cells of the lungs and discharges the contents of its reservoir. Because of this, the virus replicates and produces a negative strand RNA from the pre-existing single-strand positive RNA via the action of RNA polymerase (transcription) after it has infiltrated the host cell[14]. It forms a new, negative strand RNA, which synthesis new positive RNAs, and these new proteins are synthesised in the cell cytoplasm (translation)[15]. Specifically, the viral N protein attaches to the newly generated genomic RNA, while the viral $\mathrm{M}$ protein aids in the integration of the virus into the host cell's endoplasmic reticulum. Afterwards, these freshly produced Nucleocapsids are enveloped in the endoplasmic reticulum membrane and carried to the lumen, where they are transferred to the cell membrane through Golgi vesicles, and finally to the 
extracellular environment by exocytosis. Through the utilization of an airborne pathway, the freshly produced virus III. particles are now able to infiltrate neighbouring epithelial cells and act as a source of infectious material for community transmission.

Phases of COVID-19 progression:

\section{First phase or phase of incubation:}

This phase usually from the day of infection to the onset of first symptom. It usually lasts between 2 to 11 days and the mean incubation time is 6 days[16].

II. Second phase (Respiratory involvement phase):

The typical COVID-19 symptoms begin in this phase. The main symptoms of this disease include fever in $85 \%$ of patients, dyspnoea in 70-80\%, cough in $40-80 \%$, smell and taste dysfunction in $50 \%$, myalgia in $30 \%$, and gastrointestinal problems in $10-30 \%$. A scratchy throat, nasal congestion, and rhinorrhea are all common symptoms of upper respiratory infections, although only a minority of individuals may experience these symptoms in their whole[17]. In these patients, severe respiratory involvement and progression is noted. Ground-glass opacities on chest computed tomography (CT) scans, interlobular septal thickening and air bronchograms are some of the noteworthy results, according to the researchers[18].

\section{Third phase (Systemic inflammatory} phase):

There is some evidence to support the hypothesis that the viral infection has two pathways: one in which the virus is introduced into the upper respiratory tract and replicates there, and the other in which the host response includes systemic hyper-inflammation[19].

So far, researchers believe that COVID-19 primarily involves the entire body as an inflammatory disease. Proinflammatory cytokines are rapidly elevated when monocytes invade the lymphoid tissue, triggering the inflammatory response, and stimulating the apoptosis of $\mathrm{T}$ cells, which aid in the development of the disease[20]. This describes a cytokine storm, in which the levels of Interleukin2(IL-2), Interleukin-6(IL-6), Interleukin-7 (IL-7), Tumor necrosis factor- $\alpha$ (TNF- $\alpha$ ), Creactive protein(CRP), Ferritin, D-Dimer, and high-sensitivity cardiac troponin I increase dramatically. Adverse outcomes, as well as potential long-term multi organ damage, are frequently observed in patients who have an inflammatory response to infection. The symptoms of the SARS-CoV2 with respect to its progression are given in Table 1.

TABLE 1: TIMELINE PROGRESSION OF SYMPTOMS OF COVID-19

\begin{tabular}{|l|l|l|}
\hline $\begin{array}{l}\text { Day Of } \\
\text { Onset }\end{array}$ & \multicolumn{1}{|c|}{ Common Symptoms } & Rare Symptoms \\
\hline Day 1-4 & Fever, fatigue, muscle pain, dry cough.[21] & Nausea, diarrhea \\
\hline Day 5 & Difficulty in breathing[21] Continuation of flu like symptoms & - \\
\hline Day 6 & Breathing difficulties, persistence of cough and fever & Chest tightening, Feeling like "band" around their chest \\
\hline Day 7-9 & Persistent chest pain, shortness of breathe & Bluish discoloration of lips and face \\
\hline Day 10-11 & Worsening of breathing difficulties & Pain in abdomen, loss of appetite \\
\hline Day 12 & Persistence of cough & - \\
\hline Day 13-18 & - & - \\
\hline
\end{tabular}

\section{TIMELINE PROGRESSION OF COVID-19:}

During first four days of infection, the virus grows quickly in the body of the individual who has been infected. The SARS-CoV-2 virus is able to enter cells after binding to the ACE-2 receptor on the cell surface. Once inside, the virus takes advantage of the cell's machinery to replicate itself and spread to other cells, causing the cell to die[22].

On day 5, Acute Respiratory Distress Syndrome (ARDS) that results in pneumonia develops due to damage of the linings of lungs by the virus and decreased flow of blood to the organs[23]. 
On day 6, an uncontrolled release of pro-inflammatory cytokines in a short period of time, known as a cytokine storm, may result in the death of the person who is affected[24] Since cytokine storm will lead to the second phase of the disease, this 5-6 day period are crucial to make proper diagnosis which includes HR-CT scan, CRP test, IL-6 tests[25].

In between $7^{\text {th }}$ and $9^{\text {th }}$ day of infection, due to suppressed immunity with the use of steroids, patient may experience low-high grade fever due to bacterial infections. At this point antibiotics are of great use to treat the bacterial infections. No recovery was reported with the use of antibiotics in the early stage of infection moreover, it can build resistance to the upcoming bacterial infections.

Patients who have a worsening of their illness on day 10 may be required to be admitted to the intensive care unit (ICU). A 2-percent mortality rate is observed among individuals who reach this stage of their illness. The Wuhan research found that the majority of participants' fever subsided by Day 12.

Days 13-16, for individuals who have survived the illness, respiratory problems are usually subsiding or even disappearing. On day 17, people who recover from the COVID-19 illness are often released from the hospital around day 17 of their hospitalization. If a patient does not survive the infection, the average time from the start of symptoms to death is typically 18 days, according to the American Cancer Society.

\section{DIAGNOSTIC PARAMETERS OF COVID-19: \\ RT-PCR Test:}

Specific RT-PCR tests are to be performed on nasopharyngeal secretions to detect ARDS[26]. The reverse transcription polymerase chain reaction (RT-PCR) is a laboratory method that involves the conversion of RNA into DNA (also known as complementary DNA or cDNA) and the amplification of specific DNA targets using a polymerase chain reaction (PCR)[27]. It is done through the use of fluorescence, which is known as quantitative PCR or real-time PCR (qPCR)[28]. For more details about the interpretation of RT-PCR test results see Table 2.

\section{C- Reactive protein:}

CRP is always ordered when symptoms continue after the fifth day of therapy. When there is an infection, the degree of inflammation in the body is indicated by the presence of $\mathrm{C}$-reactive protein in the blood[29]. Because the CRP level is higher than the usual level, it may be deduced that infection is growing. Many people are surprised to learn that[30]. Creactive protein (CRP) tests yield a reading on the blood level of C-reactive protein, which is produced by the liver[31].

Normal CRP levels suggest that the patient's body is reacting favourably to the therapy, whereas elevated CRP levels indicate that further testing, such CT scans, should be done to detect infection.

The use of anti-inflammatory medicine at least twice, spaced out over a four-to-five-day period is suggested to better gauge the amount of inflammation. Also, if the CRP levels are over $70 \mathrm{mg} / \mathrm{L}$ but the SPO2 and CRP levels are both within normal range, it might mean that a cytokine storm is approaching and that medical assistance should be sought immediately. If the symptoms persist after the fifth day of treatment, CRP should be performed to assess the level of inflammation in the body and the patient's response to the current treatment[32]. For more details about the interpretation of CRP test results see Table 2.

TABLE 2 INTERPRETATION OF RT-PCR AND CRP TEST RESULTS

\begin{tabular}{|l|l|l|}
\hline Test & core & Viral load \\
\hline T-PCR & $7-24$ & High viral load \\
\hline & $4-35$ & Moderate viral load \\
\hline & 35 & Mild viral load \\
\hline $\mathrm{RP}(\mathrm{mg} / \mathrm{dL})$ & -6 & Normal \\
\hline & 26 & Mild \\
\hline & $6-100$ & Moderate \\
\hline & 100 & Severe \\
\hline
\end{tabular}

$R T-P C R$ - Reverse transcription-polymerase chain reaction $C R P$ - Creatinine Reactive protein 


\section{HR-CT Scan:}

The CT and ultra-high-resolution CT scans are currently used in addition to conventional (computed) tomography (CT) and traditional (non-computed) tomography (CT) to find out if the viral infection is present in the body. Glass-like, opaque opacities can be seen in the lung cavities, which is a crucial sign of COVID severity. The tiny ground glass indicators reveal the presence of infection in critical organs and suggest how severe and likely that infection is in individuals with COVID-19[33].

HRCT findings and CORADS scores are generally interpreted using CT measurement (which is different from the CT value detected in RT-PCR tests). The COVID-19 Reporting and Data System (CORADS), is used to identify the degree of viral infection and participation. On a scale of 1 to 5, CORAD scores range from 'negative COVID' (normal lung function) to 'typical COVID-19' (suspected viral involvement) [34].

Due to the fact that CORADS uses CT scanners alone, CT severity scores are rarely included in HRCT scans. A majority of the scores lie between 1 and 40, and the rest of the results fall between 1 and 25 . Increased lung involvement and severe COVID are generally observed with a higher score[35].

TABLE 3 INTERPRETATION OF CT TEST RESULTS

\begin{tabular}{|l|l|l|}
\hline Type & core & CT-Severity \\
\hline CT & 8 & Mild \\
SCORE: & -15 & Moderate \\
& 15 & Severe \\
\hline CO-RADS & O-RADS 1 & No \\
SEVERITY SCORE & O-RADS 2 & Low \\
& O-RADS 3 & Intermediate \\
& O-RADS 4 & High \\
& O-RADS 5 & Very high \\
& O-RADS 6 & Very high with PCR+ \\
\hline
\end{tabular}

CO-RADS - COVID-19 Reporting and Data System

A simple blood test will detect the infection if it is present. Those who have a positive result should be scanned with an HRCT during the first week of illness if their symptoms fail to improve. Because the virus often takes one week to reveal itself in the lower respiratory tract, a chest scan is extremely effective. For more details about the interpretation of CT-Test results see Table-3.

\section{IL-6 Test:}

Products which spread quickly can boost the expression of IL-6 from fibroblast, mesenchymal, endothelial, and other cells. By blocking the IL-6 pathway, we can control the effects that IL-6 has on cells. There are major consequences when there is too much IL-6 in people with COVID-19. There is also this particular form of HCG that is released in reaction to infection and tissue injury, and can be found in the blood in a soluble form[36]. It is beneficial in boosting the immune response and activating numerous systems, which aids the body in its battle against infection and disease. Acute phase reactants such as Creactive protein, serum amyloid $\mathrm{A}$, and others are generated by interleukin- 6 in the liver, and they all have a role in inflammation. It may be necessary to use other methods in order to keep IL-6 at bay in order to restrict the transcription of the virus. When a virus infects a person, IL-6 is released, which causes $\mathrm{T}$ cells to become activated and cause anaphylaxis. SARSCoV-2 infected individuals with high levels of the pro-inflammatory cytokine IL-6 had pulmonary inflammation and significant lung damage[36]. Also, individuals with SARS-CoV-2 exhibited lower levels of the cytokine suppressor of cytokine signaling-3, which dampens and suppresses the IL-6 feedback loop. IL-6, an inflammatory cytokine, was discovered to be increased in those who had experienced a severe infection. In one study, patients who had experienced a severe infection displayed higher levels of IL-6, and the existence of this connection was considered evidence of a future transition from mild infection to severe infection[37].

Ensuring a robust host response and increased survival against infection is achieved by strictly managing the IL-6 pathway. The level of IL-6 must be tightly controlled because an elevated level can lead to a hyper-inflammatory state that is 
strongly linked to sickness and other consequences. Elevated levels of the cytokine IL-6 in COVID-19 individuals can produce a pro-coagulant state that may culminate in disseminated intravascular coagulation (DIC). In patients with excessive levels of IL-6, respiratory failure and death are both more common. This is supported by other findings. In this instance, research indicates that elevated levels of IL6 correlate with an increased risk of death. IL-6 level of $5 \mathrm{pg} / \mathrm{ml}$ or less is considered normal[38]. For more details about the interpretation of IL- 6 test results see Table4.

\section{D-Dimer test:}

A protein fragment called D-dimer is, in fact, a fragment of a blood clot. After the clot degrades, D-dimer starts to repurpose itself. While D-dimer is a very reliable biomarker for both mortality and disease severity, its use is limited in some clinical settings[39]. When blood clots, Ddimer (also known as the Fibrin Dimer) is the residue of cross-linked fibrin, which is seen in the blood. People with blood clotting issues should be compelled to have a Ddimer test[40]. Although originally known as CORONA virus, this virus can also form a colony in the lungs and continue to mutate into something much more hazardous than we can possibly envision. Frequently noticed and potentially life-threatening symptoms, such as bleeding, are associated with the D-dimer test, which is why it is essential. In individuals with severe types of Covid-19, the D-dimer test is able to identify the existence of blood clots throughout the patient's body, including the lungs. Patients who have these symptoms might feel shortness of breath and difficulty breathing. The only alternative in these circumstances is a D-dimer test.

Summarizing, the D-dimer test is a mandatory and crucial component in Covid. Blood clots are present if the test result suggests a greater level of D-dimer in the body. As the levels of D-dimer increase, the amount of oxygen required by the patient increases, because of the increased clotting as well[41].

Suggested monitoring of plasma concentrations of platelet-derived peptide (PT), fibrinogen, D-dimers, and D-dimer concentrations every 48 hours is meant to help prevent thrombotic events by monitoring rising D-dimer concentrations. A rise in plasma D-dimers might possibly explain a change in anticoagulation dosage, although, at this time, there is no data to suggest that dosage adjustments are required based on D-dimers. For more details about the interpretation of D-DIMER test results see Table- 4 .

TABLE 4 INTERPRETATION OF IL-6 AND D-DIMER

\begin{tabular}{|l|l|l|}
\hline Type & Score & Severity of Inflammation \\
\hline Interleukin-6 & -7 & Normal \\
& $<15$ & Mild \\
& $15-100$ & Moderate \\
& $100-500$ & Severe \\
& 500 & Critical \\
\hline D-Dimer & 0.5 & Normal \\
& 1 & Mild \\
& 1 & Moderate-Severe \\
\hline \multicolumn{2}{|c|}{ IL-6: - Interleukin-6 } \\
& D-DIMER: - Domain dimer
\end{tabular}

\section{Serum ferritin test:}

Previous research investigations have demonstrated that high serum ferritin levels are correlated with greater COVID-19 disease severity[42]. In the course of inflammatory disorders, ferritin production might be active. Macrophages, which generate significant quantities of cytokines and constitute the bulk of immune cells in the lung parenchyma, may be responsible for the production of serum ferritin. Ferritin production may be stimulated by an inflammatory stimulation, such as interleukin-6 (IL-6). Patients with COVID19 have increased levels of interleukin-6 (IL-6), which seems to be associated with the severity of their disease. Ferritin may serve a variety of functions other than that of an iron storage protein, and as a result, it may be actively released at the site of the infection[43].

Normal levels of serum ferritin are :

Males: $20-250 \mathrm{ng} / \mathrm{mL}$

Females: $10-120 \mathrm{ng} / \mathrm{mL}$ 


\section{TREATMENT:}

\section{Remdesivir:}

Remdesivir medication should be initiated if the oxygen saturation values drop below $94 \%$ in the room air and the illness persists or worsens on the fifth day[44]. Because patients who are asymptomatic, moderately symptomatic, or who are extremely sick and have experienced multiorgan dysfunction should not be treated with psychotherapy, this service should not be offered. In addition, it can be used in patients who have mild or moderate moving toward severe infection to increase its effectiveness.

When the virus infects a human cell, it uses the cell's existing machinery to replicate its genetic material and then spreads to other cells. Various human proteins, viral proteins, and their interactions are part of the infection process at every step. RdRp, the viral protein, serves as the motor for the virus at the replication stage. RdRp attacks Remdesivir by directly attacking it. In conjunction with remdesivir, the virus's food source is replaced, thereby preventing future replication[45].

There is a viral replication period of between 1 and 7 days, followed by problems that emerge during the most crucial and severe phase of COVID-19 (post 7 to 8 days) (SIRS). Because viral replication is occurring between the second and tenth day, this medication is optimally administered during this time period[46].

If the patient has no symptoms, has just a minor case of symptoms, or has experienced multi-organ dysfunction, do not utilize this therapy. Even if it does not work the first day, it can be administered for individuals who have a mild or moderateprogressive infection after two or ten days.

As is typical, patients usually feel better after five days of beginning of infection with Covid-19, helped along by antibodies our immune system produces. In the event that fever of high grade remains even after five days, you should consider this sickness seriously and proceed appropriately.

\section{Steroid therapy:}

Symptoms of severe COVID-19 include lung damage and multiple organ failure. A systemic inflammatory response may develop in individuals with severe COVID-19. It has been hypothesized that these positive benefits may be accompanied by undesirable side effects, such as the possible capacity of corticosteroids to suppress inflammation, which has been postulated[47].

The administration of corticosteroids was linked with a mortality rate that was much lower after 28 days[48]. Several other CoV-1 and MERS-CoV infections had been tested, and all of them had come back negative, indicating that the method was ineffective. According to one research, systemic corticosteroids decreased mortality in critically sick patients with SARS-CoV-1 and influenza A (H1N1) viral pneumonia when administered early[49].

Dexamethasone (a glucocorticoid) binds to the glucocorticoid receptor (GR) on the surface of cell membranes, resulting in the creation of a complex and the translocation of the steroid inside the cell, where it is transported to the nucleus. Both transcriptional activators and transcriptional repressors, these nucleotide-based sequences have been shown to function as both. It is possible to suppress the synthesis of interleukin-1, interleukin-2, interleukin-6, interleukin-8, TNF, IFN-gamma, VEGF, and prostaglandins. Aside from that, these five measures have a significant relationship with the severity of SARS-CoV-2 infection. The creation of the glucocorticoid response element, which in turn stimulates the synthesis of anti-inflammatory cytokines such as interleukin-10 and lipocortin-1, may occur within the same time period, if this is the case[49].

If you are using dexamethasone as part of your therapy, it will bind to the membrane-associated GR on the surface of cells such as $\mathrm{T}$ lymphocytes, inhibiting receptor signalling and the immunological response produced by $\mathrm{T}$ lymphocytes. FAK (focal adhesion kinase) is activated as a 
consequence of the engagement of the glucocorticoid receptor to the integrins in the cell membrane. Since calcium and sodium move swiftly across the cell membrane, inflammation is reduced in a very short period of time[50].

\section{Anti-coagulant therapy:}

In addition, some studies discovered that ACE-2, the functional receptor for the SARS-CoV-2, was shown to be present in human tissues[51]. According to earlier study, cells in the alveolar epithelial cells of the lungs and in the enterocytes of the small intestine both express the ACE-2 enzyme in their cells[52]. The discovery of ACE-2, a new and distinct protein found in both venous and arterial endothelial cells, as well as in arterial smooth muscle cells, was also significant. The ACE-2 protein is thought to be involved in the regulation of both cardiac function and blood pressure[53]. Cervical cancer and hepatitis $C$ both activate aryl hydrocarbon receptor (AhR) independently of indoleamine 2,3-dioxygenase (IDO1). Systemic AhR Activation Syndrome is triggered by the activation of AhR, which causes the expression of many AhRdependent downstream effectors (SAAS). Injuries associated with inflammation, thromboembolism, and fibrosis may take place, and include multiple organ damage and even death. There is a strong connection between COVID-19 and coagulopathy ("coagulopathy" even though all elements of hemostasis might be impacted) which greatly raises the risk of venous thrombosis, with special focus on the development of deep vein thrombosis (DVT)[54].

Covid-19 exacerbation causes fibrin deposits to form in the alveoli and extravascular lung parenchyma in those who died. Once such deposits are dissolved, they might also contribute to the increase in Ddimer concentrations, and D-dimer concentrations are not specific of intravascular fibrin production.

According to the ISTH interim advice, anticoagulant treatment should be used for a wide spectrum of patients, especially those with significant D-dimer levels or high fibrinogen levels, who are hospitalized with COVID-19[55].

\section{Interleukin-1 antagonists:}

The inflammatory cascade is triggered by both IL- $1 \alpha$ and IL- $1 \beta$ acting on the IL-1 receptor 1 to increase the production of inflammatory cytokines including $\mathrm{TNF} \alpha[56]$. Anakinra is an interleukin-1 receptor antagonist (also known as a receptor antagonist) that has been approved by the Food and Drug Administration(FDA) for the treatment of rheumatoid arthritis (RA)[57]. A small casecontrol study was conducted to determine whether COVID-19 could be used to treat severe COVID-19 because the disease is driven by cytokine production, specifically interleukin (IL)-1. The use of COVID-19 in severe COVID-19 was investigated on the basis that COVID-19 is off-label in this disease. According to this clinical trial, anakinra substantially reduced the need for invasive mechanical ventilation and the risk of mortality in patients with severe COVID19[58]. Several clinical trials found that administering anakinra improved death rates in COVID-19 patients[59].

\section{Monoclonal antibodies:}

Monoclonal antibodies 'neutralize' and bind to the SARS-CoV-2 virus, preventing it from reproducing. This therapeutic approach has the potential to substantially increase the effectiveness of attempts to bring the pandemic under control, as well as to slow the development of this fatal illness in individuals who have mild to severe sickness. Infection with COVID-19[60].

\section{Tocilizumab:}

Tocilizumab, a monoclonal antibody against the IL-6 receptor, inhibits both cell membrane and soluble IL-6 receptor binding, resulting in a reduction in IL-6 production[61]. China had noted improved patient outcomes in individuals with COVID-19 who were treated with 
tocilizumab[62]. Individuals who got tocilizumab shown a substantial decrease in the likelihood of hospitalization for invasive mechanical ventilation or death when compared to those who received just standard of care, according to a new retrospective cohort study published in The Lancet[63].

\section{Janus kinase inhibitors:}

Several researchers believe that the kinase inhibitors might cure COVID-19 by reducing the phosphorylation of critical proteins that play a role in immune response and inflammation[64].

\section{Baricitinib:}

When baricitinib was combined with the prodrug remdesivir, patients in the Covid-19 study who were receiving highflow oxygen or non-invasive ventilation had significantly faster and better recovery times as well as clinical status improvement[65]. It is a specific inhibitor of Janus kinases 1 and 2, Janus kinase 2 in particular. It is being passed around Interferon-gamma $(\mathrm{INF}-\gamma)$, interferon-alpha (INF- $\alpha)$, and granulocyte macrophage colony-stimulating factor (GM-CSF) are cytokines that are unable to penetrate the cell membrane, causing them to be blocked in their intracellular signalling pathways. Furthermore, studies have shown that it may boost the lymphocyte count while also preventing the virus from entering the cell, which is beneficial[66].

\section{MANAGEMENT OF SARS-COV-2 BASED ON SEVERITY:}

During the asymptomatic or presymptomatic stage, in the absence of clinical symptoms associated with COVID19 or any other diseases, positive SARSCoV-2 test findings should be considered cause for isolation, and one should be on the alert for any new symptoms[57]. Immune boosters and vitamin supplements should be given.

For mild illness of Covid-19, supportive care to be given and individuals are to be isolated. Elderly patients and immuno-compromised patients are to be monitored closely. Regular monitoring of laboratory findings is required. Treatment with REGN-COV2 (casirivimab and imdevimab), bamlanivimab /etesevimab /sorovimab, may be explored for outpatients[57]. Symptomatic treatment like acetaminophen for pyrexia can be used.

While the infection is at moderate stage, patients should be hospitalized for close monitoring and supportive care. Monitor for the risk of thromboembolic events. Maintain prophylaxis of thromboembolism. Remdesivir and dexamethasone can be given for those who were hospitalized and require supplemental oxygen. Patients needing supplemental oxygen but not receiving HFNC, NIPPV, IMV or ECMO are advised to use either dexamethasone plus remdesivir or dexamethasone plus remdesivir, or, alternatively, dexamethasone plus remdesivir, according to the NIH's Covid-19 therapeutic recommendations group[67].

To treat severe illness, patients require hospitalization and prophylactic anti-coagulant therapy should be given. In individuals who do not need intubation, HFNC or NIPPV may be explored as options[57]. In hospitalised patients who require oxygen via non-invasive or invasive ventilation, the NIH Covid-19 Treatment Guidelines Panel advises the use of dexamethasone. Also suggested in hospitalised patients on HFNC or NIPPV with signs of disease progression, is combination treatment that includes dexamethasone with one of the following: remdesivir, baricitinib, or tocilizumab. baricitinib with remdesivir may be administered in non-intubated patients if carotenoids cannot be used[67]. If there is a possibility of a subsequent bacterial infection, empiric antibiotic treatment should be explored.

\section{CONCLUSIONS}

Mild symptoms like pyrexia at the initial days of infection should be treated 
with acetaminophen. Antibiotics does not play any role in treating the infection at the early stages instead they can create resistance for the opportunistic infections that may infect at the later phases of the treatment. Treatment with REGN-COV2 (casirivimab and imdevimab), bamlanivimab/ etesevimab or sorovimab, as well as another alternative, may be explored for outpatients who are at risk of disease development and who are willing to undergo outpatient vigilant monitoring. At the moderate illness stage, prophylactic treatment for thromboembolism with appropriate anti-coagulants is to be given. Remdesivir and dexamethasone cab be given for those who were hospitalized and require supplemental oxygen. Regular monitoring of the levels of inflammation by measuring C-reactive protein, D-Dimer, serum ferritin, and CT severity score during 5-10 days of Covid-19 infection plays a vital role as the risk of cytokine shower might reach to its heights during these days. Treating the infection of SARS-CoV-2 by understanding the timeline progression of the disease might create huge impact on the treatment outcomes. Giving immune boosters as a prophylactic treatment and also the asymptomatic stage of the treatment helps in reducing the severity of the disease. However, understanding the timeline progression of the disease and treating the disease with appropriate regimen by giving the right drug at right time can show a major difference in the therapeutic outcome.

\section{ACKNOWLEDGEMENTS}

The authors acknowledge the support received from Vikas Institute of Pharmaceutical Sciences and extend our sincere gratitude for their support and encouragement throughout the process of this work.

\section{Conflict of Interest: None}

Source of Funding: None

\section{REFERENCES}

1. World Health Organization (2021) Coronavirus disease (COVID-19) pandemic. In: World Heal. Organ. Eur. https://www.euro.who.int/en/healthtopics/health-emergencies/coronaviruscovid-19/novel-coronavirus-2019-ncov. Accessed 22 Jul 2021

2. Pai Liu, Payton Beeler, Rajan K. Chakrabarty. (2020) COVID-19 Progression Timeline and Effectiveness of Response-toSpread Interventions across the United States. medRxiv 03:1-14

3. Andrews, M. A., Areekal, B., Rajesh, K. R., Krishnan, J., Suryakala, R., Krishnan, B., Muraly, C. P., \& Santhosh, P. V. (2020) First confirmed case of COVID-19 infection in India: A case report. Indian J Med Res 151:490-492

4. Calisher, Charles, Carroll D, Colwell R, et al (2020) Statement in support of the scientists, public health professionals, and medical professionals of China combatting COVID-19. Lancet 395:e42-e43

5. Chinazzi, Matteo, Davis JT, Ajelli M, et al (2020) The effect of travel restrictions on the spread of the 2019 novel coronavirus (COVID-19) outbreak. Science (80- ) 368:395-400

6. Gilbert, Marius, Pullano G, Pinotti F, et al (2020) Preparedness and vulnerability of African countries against importations of COVID-19: a modelling study. Lancet 395:871-877

7. World Health Organization (2020) Statement on the second meeting of the International Health Regulations (2005) Emergency Committee regarding the outbreak of novel coronavirus (2019nCoV). In: World Heal. Organ. https://www.who.int/news/item/30-01-2020statement-on-the-second-meeting-of-theinternational-health-regulations-(2005)emergency-committee-regarding-theoutbreak-of-novel-coronavirus-(2019-ncov). Accessed 22 Jul 2021

8. World Health Organization (2021) Total Covid Cases. In: WHO Coronavirus Dashboard. https://covid19.who.int/. Accessed 22 Jul 2021

9. BMJ Best Practice (2021) Coronavirus disease 2019 (COVID-19). BMJ Publ Gr. https://doi.org/10.1007/978-3-319-957142_300044 
10. Taubenberger JK (2020) Human Coronavirus Types. In: CDC. https://www.cdc.gov/coronavirus/types.html . Accessed 22 Jul 2021

11. Zhu N, Zhang D, Wang W, et al (2020) A Novel Coronavirus from Patients with Pneumonia in China, 2019. N Engl J Med 382:727-733

12. Parasher A (2021) COVID-19: Current understanding of its Pathophysiology, Clinical presentation and Treatment. Postgrad Med J 97:312-320

13. Li W, Moore MJ, Vasilieva N, et al (2003) Angiotensin-converting enzyme 2 is a functional receptor for the SARS coronavirus. Nature 426:450-454

14. Buckland R, Wild TF (1997) Is CD46 the cellular receptor for measles virus? Virus Res 48:1-9

15. Yang N, Shen HM (2020) Targeting the endocytic pathway and autophagy process as a novel therapeutic strategy in COVID19. Int J Biol Sci 16:1724-1731

16. Lai CC, Shih TP, Ko WC, Tang HJ, Hsueh PR (2020) Severe acute respiratory syndrome coronavirus 2 (SARS-CoV-2) and coronavirus disease-2019 (COVID-19): The epidemic and the challenges. Int $J$ Antimicrob Agents 55:105924

17. Lippi G, Sanchis-Gomar F, Henry BM (2020) COVID-19: unravelling the clinical progression of nature's virtually perfect biological weapon. Ann Transl Med 8:693693

18. Bao C, Liu X, Zhang H, Li Y, Liu J (2020) Coronavirus Disease 2019 (COVID-19) CT Findings: A Systematic Review and Metaanalysis. J Am Coll Radiol 17:701-709

19. Siddiqi HK, Mehra MR (2020) COVID-19 illness in native and immunosuppressed states: A clinical-therapeutic staging proposal. J Hear Lung Transplant 39:405407

20. Basso C, Leone O, Rizzo S, De Gaspari M, Van Der Wal AC, Aubry MC, Bois MC, Lin PT, Maleszewski JJ, Stone JR (2020) Pathological features of COVID-19associated myocardial injury: A multicentre cardiovascular pathology study. Eur Heart J 41:3827-3835

21. ARIA BENDIX AB (2020) A day-by-day breakdown of coronavirus symptoms shows how the disease, COVID-19, goes from bad to worse. businessinsider.in
22. Franz Wiesbauer SJ (2020) COVID-19 disease progression. In: medmastery.com. https://www.medmastery.com/guide/covid19-clinical-guide/covid-19-diseaseprogression. Accessed 20 Jul 2021

23. Li X, Ma X (2020) Acute respiratory failure in COVID-19: Is it "typical" ARDS? Crit Care 24:1-5

24. Ye Q, Wang B, Mao J (2020) The pathogenesis and treatment of the 'Cytokine Storm' in COVID-19.' J Infect 80:607-613

25. Ragab D, Salah Eldin H, Taeimah M, Khattab R, Salem R (2020) The COVID-19 Cytokine Storm; What We Know So Far. Front Immunol 11:1-4

26. US FDA (2021) Emergency Use Authorization (EUA) SUMMARY COVID19 RT-PCR TEST (Laboratory Corporation Of America). In: Lab. Corp. Am. https://www.fda.gov/media/136151/dhttps:// www.fda.gov/media/136151/download. Accessed 27 Jul 2021

27. Thermo Fisher Scientific (2021) Basic Principles of RT-qPCR. In: Thermofisher. https://www.thermofisher.com/in/en/home/b rands/thermo-scientific/molecular-

biology/molecular-biology-learningcenter/molecular-biology-resourcelibrary/spotlight-articles/basic-principles-rtqpcr.html. Accessed 27 Jul 2021

28. Emery, S. L., Erdman, D. D., Bowen, M. D., Newton, B. R., Winchell, J. M., Meyer, R. F., ... \& Anderson LJ (2004) Real-time reverse transcription-polymerase chain reaction assay for SARS-associated coronavirus. Emerg Infect Dis 10:311

29. Mortensen RF (2001) C-reactive protein, inflammation, and innate immunity. Immunol Res 24:163-176

30. Ali N (2020) Elevated level of C-reactive protein may be an early marker to predict risk for severity of COVID-19. J Med Virol. https://doi.org/10.1002/jmv.26097

31. Slevin M, Skok M, Ashworth JJ, Sproston NR (2018) Role of C-Reactive Protein at Sites of Inflammation and Infection. Front Immunol 9:754

32. Axonlab (2021) MONITORING THE "CYTOKINE STORM": C-reactive protein (CRP) and dysregulation of immune response in COVID-19. In: Axon Lab AG. https://ch.axonlab.com/en/blog/detail/sCateg ory/7087/blogArticle/764. Accessed 27 Jul 2021 
33. Francone $M$, Iafrate $F$, Masci GM, et al (2020) Chest CT score in COVID-19 patients: correlation with disease severity and short-term prognosis. Eur Radiol 30:6808-6817

34. Ricardo Peris S, Estrella F-F, Gustavo Juan S, Maria Luisa Domingo M, Lidia Navarro V (2018) Visual HRCT Score to Determine Severity and Prognosis of Idiopathic Pulmonary Fibrosis. Int J Respir Pulm Med 5:084

35. Yang, R., Li, X., Liu, H., Zhen, Y., Zhang, X., Xiong, Q., ... \& Zeng W (2020) Chest CT severity score: an imaging tool for assessing severe COVID-19. Radiol Cardiothorac Imaging 2:e200047

36. Vatansever HS, Becer E (2020) Relationship between IL-6 and COVID-19: To be considered during treatment. Future Virol 15:817-822

37. Chen LYC, Hoiland RL, Stukas S, Wellington CL, Sekhon MS (2021) Assessing the importance of interleukin-6 in COVID-19. Lancet Respir Med 9:e13

38. Herold, T., Jurinovic, V., Arnreich, C., Hellmuth, J. C., von Bergwelt-Baildon, M., Klein, M., \& Weinberger T (2020) Level of IL-6 predicts respiratory failure in hospitalized symptomatic COVID-19 patients. medRxiv. https://doi.org/doi.org/10.1101/2020.04.01.2 0047381

39. Yu HH, Qin C, Chen M, Wang W, Tian DS (2020) D-dimer level is associated with the severity of COVID-19. Thromb Res 195:219-225

40. Suborna Fermi (2021) Importance of ddimer test in Covid-19. In: diagnosticcentres.in.

https://www.diagnosticcentres.in/healthcarearticle/importance-of-d-dimer-test-in-covid19. Accessed 24 Jul 2021

41. Drs. Morayma Reyes Gil, Aggie Lee, Nigel Key, Dan Sabath, Cindy Leissinger, Oksana Volod, Geoff Wool LBK (2020) COVID-19 and D-dimer: Frequently Asked Questions. In: Am. Soc. Hematol. https://www.hematology.org/covid-

19/covid-19-and-d-dimer. Accessed 24 Jul 2021

42. Forman DT, Parker SL (1980) The measurement and interpretation of serum ferritin. Ann Clin Lab Sci 10:345-350

43. Rosário C, Zandman-Goddard G, MeyronHoltz EG, P D'cruz D, Shoenfeld Y (2013)
The Hyperferritinemic Syndrome: macrophage activation syndrome, Still's disease, septic shock and catastrophic antiphospholipid syndrome. BMC Med 11:1-11

44. MOHFW A and I (2021) Advisory for Rational use of Remdesivir for COVID-19 Treatment. mohfw.gov.in 2

45. Victoria Rees (2020) Mechanism of action revealed for remdesivir, potential coronavirus drug. In: drugtargetreview. https://www.drugtargetreview.com/news/56 798/mechanism-of-action-revealed-forremdesivir-potential-coronavirus-drug/. Accessed 24 Jul 2021

46. Goldman JD, Lye DCB, Hui DS, et al (2020) Remdesivir for 5 or 10 Days in Patients with Severe Covid-19. N Engl J Med 383:1827-1837

47. COVID-19 Treatment Guidelines Panel (2020) Corticosteroids. In: Natl. Institutes Heal.

https://www.covid19treatmentguidelines.nih .gov/therapies/immunomodulators/corticost eroids/. Accessed 24 Jul 2021

48. David J Cennimo, Scott J Bergman MSB (2021) What is the role of corticosteroids (such as dexamethasone) in the treatment of coronavirus disease 2019 (COVID-19)? In: Medscape.

https://www.medscape.com/answers/250011 4-197459/what-is-the-role-ofcorticosteroids-such-as-dexamethasone-inthe-treatment-of-coronavirus-disease-2019covid-19. Accessed 24 Jul 2021

49. Donavon B. Johnson; Michael J. Lopez; Brendan Kelley. (2020) Dexamethasone. StatPearls Publ.

50. Kino T, Burd I, Segars JH, Tliba O (2021) Molecular Sciences Dexamethasone for Severe COVID-19: How Does It Work at Cellular and Molecular Levels? Int J Mol Sci 22:6764

51. Simon Rico-Mesa J, Rosas D, AhmadianTehrani A, White A, Anderson AS, Chilton $\mathrm{R}$ (2020) The Role of Anticoagulation in COVID-19-Induced Hypercoagulability. Curr Cardiol Rep 22:1-6

52. Fouchier RAM, Kuiken T, Schutten M, Van Amerongen G, Van Doornum GJJ, Van Den Hoogen BG, Peiris M, Lim W, Stöhr K, Osterhaus ADME (2003) Koch's postulates fulfilled for SARS virus. Nature 423:240

53. Crackower MA, Sarao R, Oliveira-dosSantos AJ, Da Costa J, Zhang L (2002) 
Angiotensin-converting enzyme 2 is an essential regulator of heart function. Nature 417:822-828

54. Hamming I, Timens W, Bulthuis M, Lely AT, Navis GJ, Van Goor H (2004) Tissue distribution of ACE2 protein, the functional receptor for SARS coronavirus. A first step in understanding SARS pathogenesis. J Pathol J Pathol 203:631-637

55. Barrett, C. D., Moore, H. B., Yaffe, M. B., \& Moore, E. E (2020) ISTH interim guidance on recognition and management of coagulopathy in COVID-19. J Thromb Haemost 18:1023-1026

56. Baskar, Shankar, Klein AL, Zeft A (2016) The Use of IL-1 Receptor Antagonist (Anakinra) in Idiopathic Recurrent Pericarditis: A Narrative Review. Cardiol Res Pract. https://doi.org/10.1155/2016/7840724

57. Cascella, M., Rajnik, M., Aleem, A., Dulebohn, S., \& Di Napoli, R (2021) Features, Evaluation, and Treatment of Coronavirus (COVID-19). StatPearls Publ.

58. Huet, T., Beaussier, H., Voisin, O., Jouveshomme, S., Dauriat, G., Lazareth, I., ... \& Hayem, G (2020) Anakinra for severe forms of COVID-19: a cohort study. Lancet Rheumatol 2:e393-e400

59. Cavalli, G., De Luca, G., Campochiaro, C., Della-Torre, E., Ripa, M., Canetti, D., ... \& Dagna, L. (2020) Interleukin-1 blockade with high-dose anakinra in patients with COVID-19, acute respiratory distress syndrome, and hyperinflammation: a retrospective cohort study. Lancet Rheumatol 2:e325-e331

60. Apollo Pulmonologist (2021) Monoclonal Antibody Cocktail Shows Promise in Fight Against COVID-19. In: Askapollo. https://healthlibrary.askapollo.com/monoclo nal-antibody-cocktail-

treatment/\#: :text=Monoclonal antibodies "neutralize" and bind,to moderate COVID19 infection. Accessed 24 Jul 2021

61. Gupta, Shruti, Leaf DE (2021) Tocilizumab in COVID-19: some clarity amid controversy. Lancet 397:1599-1601
62. Xu X, Han M, Li T, et al (2020) Effective treatment of severe COVID-19 patients with tocilizumab. Proc Natl Acad Sci U S A 117:10970-10975

63. Guaraldi, G., Meschiari, M., Cozzi-Lepri, A., Milic, J., Tonelli, R., Menozzi, M., ... \& Mussini, C. (2020) Tocilizumab in patients with severe COVID-19: a retrospective cohort study. Lancet Rheumatol 2:e474e484

64. COVID-19 Treatment Guidelines Panel (2021) Kinase Inhibitors: Baricitinib and Other Janus Kinase Inhibitors, and Bruton's Tyrosine Kinase Inhibitors. In: Natl. Institutes Heal. https://www.covid19treatmentguidelines.nih .gov/therapies/immunomodulators/kinaseinhibitors. Accessed 24 Jul 2021

65. Kalil, A. C., Patterson, T. F., \& Mehta, A. K. (2021) Baricitinib plus Remdesivir for Hospitalized Adults with Covid-19. N Engl J Med 384:795-807

66. Setu K Patolia, Aniruddh Kapoor, Zab Mosenifar (2021) What is the role of baricitinib in the treatment of COVID-19? In:

Medscape. https://www.medscape.com/answers/250011 7-201198/what-is-the-role-of-baricitinib-inthe-treatment-of-covid-19. Accessed 24 Jul 2021

67. COVID-19 Treatment Guidelines Panel (2021) Therapeutic Management of Hospitalized Adults With COVID-19. In: Natl. Institutes Heal. https://www.covid19treatmentguidelines.nih .gov/management/clinicalmanagement/hospitalized-adults-therapeutic-management/. Accessed 24 Jul 2021

How to cite this article: Pavani Polipilli, Vishnu Vamsi Nannur, Bharathi Vudi et.al. Timeline approach for the treatment of COVID-19 - an overview. International Journal of Research and Review. 2022; 9(2): 143-155. DOI: https://doi.org/10.52403/ijrr.20220221 